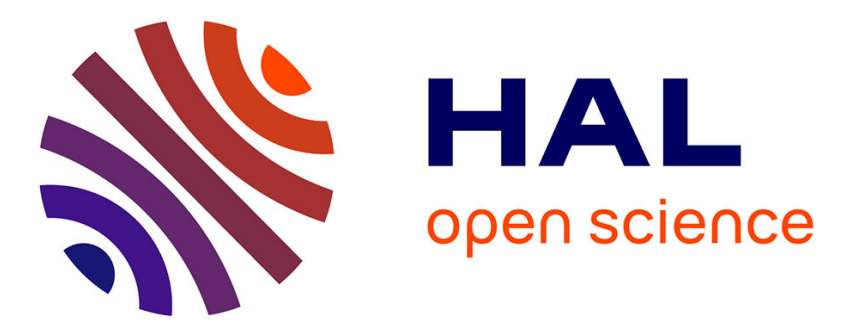

\title{
Terahertz tomographic imaging of XVIIIth Dynasty Egyptian sealed pottery
}

Jean-Pascal Caumes, Ayesha Younus, Simon Salort, Bruno Chassagne, Benoît Recur, Anne Ziéglé, Alain Dautant, Emmanuel Abraham

\section{- To cite this version:}

Jean-Pascal Caumes, Ayesha Younus, Simon Salort, Bruno Chassagne, Benoît Recur, et al.. Terahertz tomographic imaging of XVIIIth Dynasty Egyptian sealed pottery. Applied optics, 2011, 50 (20), pp.3604-3608. 10.1364/AO.50.003604 . hal-00619411

\section{HAL Id: hal-00619411 https://hal.science/hal-00619411}

Submitted on 6 Sep 2011

HAL is a multi-disciplinary open access archive for the deposit and dissemination of scientific research documents, whether they are published or not. The documents may come from teaching and research institutions in France or abroad, or from public or private research centers.
L'archive ouverte pluridisciplinaire HAL, est destinée au dépôt et à la diffusion de documents scientifiques de niveau recherche, publiés ou non, émanant des établissements d'enseignement et de recherche français ou étrangers, des laboratoires publics ou privés. 


\title{
Terahertz tomographic imaging of XVIIIth Dynasty Egyptian sealed pottery
}

\author{
Jean-Pascal Caumes, ${ }^{2}$ Ayesha Younus, ${ }^{1}$ Simon Salort, ${ }^{2}$ Bruno Chassagne, ${ }^{2}$ \\ Benoît Recur, ${ }^{3}$ Anne Ziéglé, ${ }^{5}$ Alain Dautant, ${ }^{4}$ and Emmanuel Abraham ${ }^{1, *}$ \\ 'Laboratoire Ondes et Matière d'Aquitaine, Université de Bordeaux, CNRS UMR 5798, \\ 351 Cours de la Libération, 33405 Talence, France \\ ${ }^{2}$ ALPhANOV, Centre Technologique Optique et Lasers, 351 Cours de la Libération, 33405 Talence, France \\ ${ }^{3}$ LaBRI, Université de Bordeaux, CNRS UMR 5800, 351 Cours de la Libération, 33405 Talence, France \\ ${ }^{4}$ Institut de Biochimie et Génétique Cellulaires, Université de Bordeaux, CNRS \\ UMR 5095, 351 Cours de la Libération, 33405 Talence, France \\ ${ }^{5}$ Museum of Aquitaine, 20 Cours Pasteur, 33000 Bordeaux, France \\ *Corresponding author: em.abraham@loma.u-bordeaux1.fr \\ Received 13 April 2011; accepted 26 May 2011; \\ posted 31 May 2011 (Doc. ID 145771); published 7 July 2011
}

\begin{abstract}
A monochromatic millimeter-wave imaging system coupled with an infrared temperature sensor has been used to investigate historic objects preserved at the Museum of Aquitaine (France). In particular, two-dimensional and three-dimensional analyses have been performed in order to reveal the internal structure of nearly 3500-year-old sealed Egyptian jars. (c) 2011 Optical Society of America

OCIS codes: $\quad 110.6795,110.6955,100.6890,120.5800$.
\end{abstract}

\section{Introduction}

Art scientists, historians, and curators have always been interested in the precise determination of the material composition and substructure analysis of historic objects. This scientific approach is essential as it can be employed to reveal the history of the sample, investigate the original material properties, and even discover how the object has been restored in past centuries.

In this field of art conservation, terahertz $(\mathrm{THz})$ imaging techniques have already been applied for the analysis of artworks such as fresco [1,2], canvas paintings $[\underline{3}, 4]$, and old parchments [5] . However, very few studies can be found on $\mathrm{THz}$ imaging in anthropology and paleontology [6] but this spectral range can offer unique advantages compared to the x-ray gold standard, which is not recommended

0003-6935/11/203604-05\$15.00/0

(C) 2011 Optical Society of America owing to the fragility/uniqueness of the samples and the problem of sample radiometric dating after x-ray irradiation [7].

In most $\mathrm{TH} z$ imaging systems, a broadband timedomain spectrometer is employed to record the $\mathrm{THz}$ electric field transmitted (or reflected) by the sample. Although the main advantage of such THz-pulsed imaging is to provide a spectroscopic analysis of the object, this technique is also complicated, expensive, and time consuming. Recently, we developed an alternative $\mathrm{THz}$ imaging system based on a millimeter continuous-wave source coupled with an infrared thermal sensor. This device has especially been used for three-dimensional (3D) $\mathrm{THz}$ imaging of opaque objects using computed tomography (CT) [8], which was first demonstrated in 2002 [9].

The CT method makes it possible to obtain crosssectional images by measuring the transmitted amplitude of the $\mathrm{THz}$ wave at multiple projection angles. Although $\mathrm{THz} \mathrm{CT}$ seems powerful, most of the published results concerned the investigation of 
simple manufactured phantom objects, such as foam or polyethylene cylinders, drilled with metallic bars $[10,11]$ or filled with specific chemical substances such as lactose or lactose powder $[12,13]$. The main reason is the limitation caused by the diffraction effects and Fresnel losses experienced by the propagation of the $\mathrm{THz}$ wave through the sample. As soon as the refractive index of the sample is in the order or greater than 1.5, which represents the majority of realistic samples, the $\mathrm{THz}$ beam is strongly refracted by the sample and the transmitted signal is very difficult to detect.

In this paper, we demonstrate that, in spite of this inevitable limitation, it is possible to efficiently use $\mathrm{THz} \mathrm{CT}$ with real objects of interest for $\mathrm{THz}$ radiation, such as antiquities. As pointed out previously, such an application of $\mathrm{THz}$ imaging has been underdeveloped up to this time. The portable $\mathrm{THz}$ scanner has been transferred to the Museum of Aquitaine in Bordeaux (France) in order to perform in situ twodimensional (2D) and 3D imaging of real artworks, such as pieces of pottery, jars, amulets, etc. Two ancient Egyptian pottery bottles there have been specially selected in order to demonstrate the potential of $\mathrm{THz}$ imaging for the detection of hidden materials in historic museum pieces.

\section{Experimental Setup}

The millimeter-wave tomographic scanner (shortly called "THz scanner") is based on a compact millimeter-wave Gunn diode $(110 \mathrm{GHz}, 20 \mathrm{~mW})$ coupled with a horn antenna [Fig. 1(a)]. The output beam is collimated using an off-axis parabolic mirror $\mathrm{M}\left(f^{\prime}=\right.$ $150 \mathrm{~mm})$ and then focused with a Teflon lens $\mathrm{L}\left(f^{\prime}=\right.$ $60 \mathrm{~mm}$ ) on the sample $\mathrm{S}$, which is positioned on a three-axes $X Y-\theta$ motorized stage. The angle $\theta$ corresponds to a rotation around the vertical $Y$-axis. Figure 1(b) shows the 2D transversal profile of the $\mathrm{THz}$ beam at the beam waist visualized using a photothermal $\mathrm{THz}$ convertor (TeraCAM-ALPhANOV, [14]). This result shows that, at the sample position S, the beam profile is homogeneous with a Gaussian circular shape $(4 \mathrm{~mm}$ beam diameter, measured at FWHM) in agreement with the theoretical values obtained from the propagation of Gaussian beams. This indicates that the spatial resolution of the $\mathrm{THz}$ scanner is limited to a few millimeters owing to the long wavelength of the emitting source. Consequently, the system is more adapted for the visualization of subcentimeter structures within larger-sized objects, typically more than $100 \mathrm{~mm} \times 100 \mathrm{~mm} \times 100 \mathrm{~mm}$. Symmetrically, the focal volume is imaged using a similar arrangement on a commercial low-cost pyroelectric sensor (Spectrum Detector, Inc.). For final data acquisition, the $\mathrm{THz}$ beam is modulated at $20 \mathrm{~Hz}$ by an optical chopper and the amplitude of the transmitted $\mathrm{THz}$ is acquired with a lock-in amplifier.

A 2D transmission image of the sample is obtained by moving the object in the $X$ and $Y$ directions with a scan step of generally $1 \mathrm{~mm}$ in both directions. With a scan speed of 5 pixels/s, the acquisition time
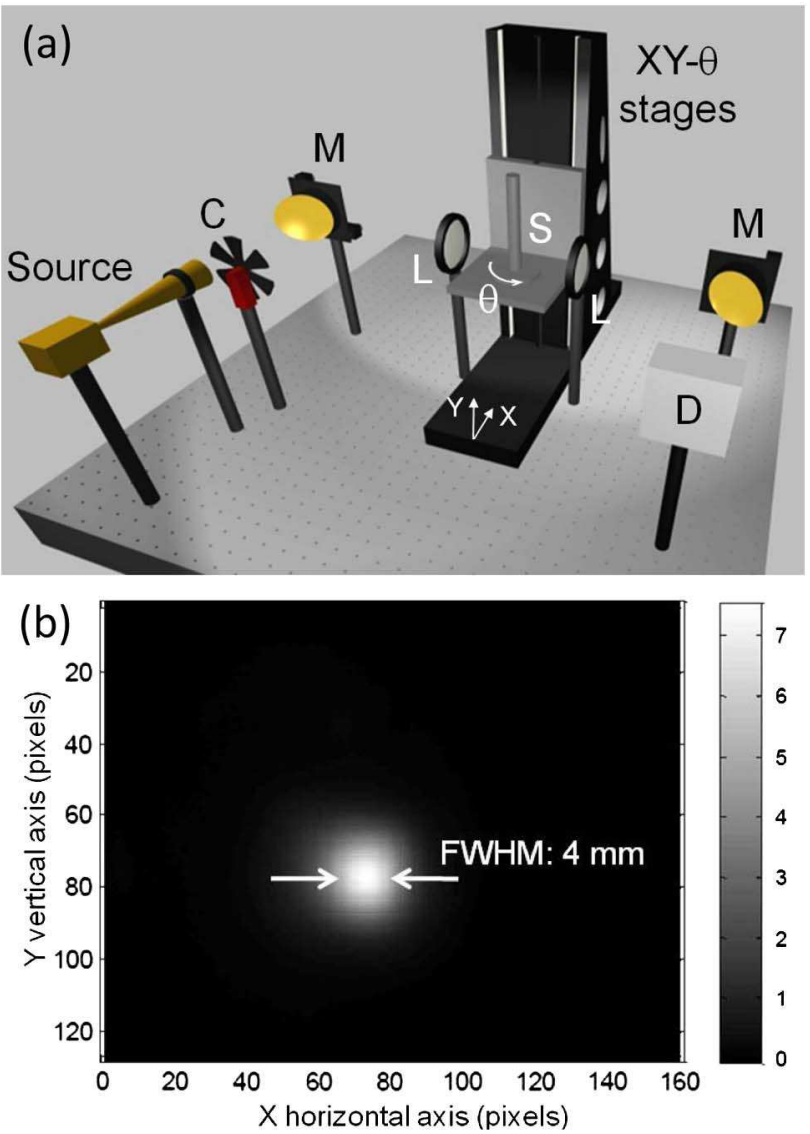

Fig. 1. (Color online) (a) Experimental setup. C, optical chopper; L, Teflon lens $\left(f^{\prime}=60 \mathrm{~mm}\right) ; \mathrm{M}$, off-axis parabolic mirror $\left(f^{\prime}=150 \mathrm{~mm}\right) ; \mathrm{S}$, sample; $\mathrm{D}$, pyroelectric detector coupled to a lock-in amplifier. (b) $2 \mathrm{D}$ spatial profile of the $\mathrm{THz}$ beam waist at the sample position visualized with a photothermal $\mathrm{THz}$ convertor (Teracam).

for a 100 pixels $\times 100$ pixels $2 \mathrm{D}$ image size is about $30 \mathrm{~min}$. For 3D reconstruction, the sample is rotated in order to provide a different visualization of the object. From these tilted series, we are able to construct the sinogram of the object that represents, for a given horizontal slice, the evolution of the transmitted $\mathrm{THz}$ amplitude as a function of the rotation angle. Here, to get a reasonable acquisition time for $3 \mathrm{D}$ imaging, we selected a rotation step of $10^{\circ}$. In this case, we obtained the corresponding 18 projections in nearly $9 \mathrm{~h}$.

This limited number of projections induces another important limitation for $\mathrm{THz} \mathrm{CT}$. Usually, the back-projection of the filtered projections (BFP) is employed as the standard 3D reconstruction method [15]. This reconstruction process is based on the inverse Radon transform [16], which computes the final pixel values from the filtered projections. It is widely developed in x-ray CT scan imaging and also commonly used in $\mathrm{THz} \mathrm{CT}$ since it is proposed in most of CT software tools. However, in x-ray CT, it is well-known that BFP suffers from several disadvantages, such as beam hardening, noise sensitivity, and geometric degradation in case of an insufficient number of projections. We recently pointed out that 
alternative iterative reconstruction methods, such as the simultaneous algebraic reconstruction technique (SART) [17], can be applied to $\mathrm{THz} \mathrm{CT}$ with equivalent accuracy and quality as BFP [8]. Especially for a limited number of projections (typically less than 25), we emphasized a quantitative degradation of the $\mathrm{BFP}$ reconstruction, whereas the SART method can already offer optimized reconstruction quality. Consequently, in this paper, we selected the SART iterative method for $3 \mathrm{D}$ reconstruction in order to reduce the acquisition time (i.e., the projection number) without noticeable quality and accuracy losses.

\section{Results and Discussion}

At the Museum of Aquitaine, many historic art samples have been scanned, from ancient Egyptian and Roman objects to more contemporary ones such as an apothecary jar (from 1920). However, in this paper, we will only focus on two sealed Egyptian pieces of pottery from the XVIIIth Dynasty (New Kingdom period).

The original use of these two jars remains a mystery for curators. Without any specific decoration, they look like simple red clay vessels hermetically sealed with a clay cork [Figs. 2(a) and 3(a)]. Their shape (a jar with a neck) indicates that they were most likely used for liquids, not ointment, perfumed cream, or unguent, because it would not allow easy access to these less liquid contents for skin application. However, the existence of Menkheperre Tuthmosis III's cartouche (1479-1425 B.C.) on the pottery's clay corks allow us to infer that these objects were probably very important, maybe used
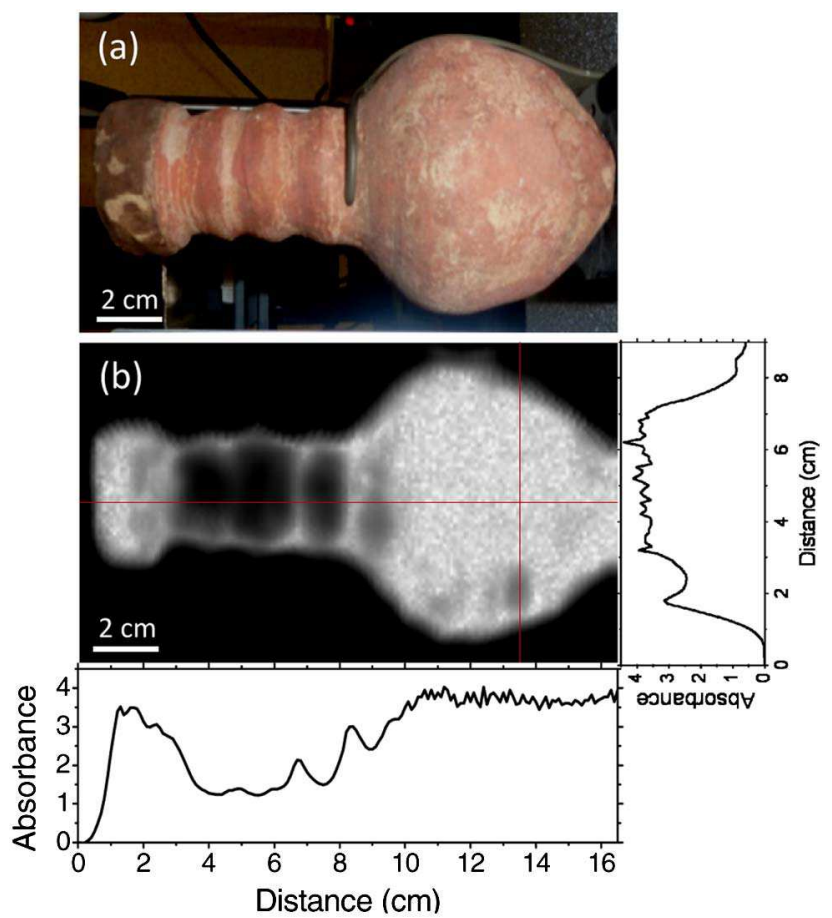

Fig. 2. (Color online) (a) Photograph of the Egyptian jar (inventory number 8606 ). (b) $2 \mathrm{D} \mathrm{THz}$ transmission image and intensity profiles (absorbance) along the horizontal and vertical red lines. during funerary rituals. Indeed, a sticker under one of the objects indicates that they were purchased in 1861 in Gournah, on the famous necropolis of Thebes (on the west bank of Luxor) [18]. Thus, according to experts, these nearly 3500-year-old pottery bottles probably did not contain viscera-usually preserved in canopic jars-but most likely food offerings.

\section{A. 2D THz Transmission Imaging}

The first sealed jar (museum inventory number 8606) is shown in Fig. 2(a). It is worth mentioning that, by gently shaking the object, it was not possible to conclude if it was filled or not. Neither internal sound nor moving materials could be noticed. For the $\mathrm{THz}$ experiment, the object was horizontally positioned inside the $\mathrm{THz}$ scanner in order to determine the presence of internal contents. Indeed, due to gravitation effects, mobile contents should have spread along the internal volume of the jar. Figure 2(b) represents the $\mathrm{THz}$ transmission image plotted in logarithmic scale with the white color indicating a decrease of the transmitted signal. The image can be decomposed into three parts: (1) the sealed clay cork where the $\mathrm{THz}$ transmission is very low probably due to the large thickness of the object in this area, (2) the neck which seems empty owing to the higher $\mathrm{THz}$ transmission, (3) the bottom of the jar which is certainly filled with a solid material owing to the low $\mathrm{THz}$ transmission. Moreover, this material seems to be attached to the bottom since a liquid or mobile contents would have spread owing to the horizontal orientation of the object. The solid contents fill the bottom cavity of the jar but not the upper neck. A more precise analysis of the $\mathrm{THz}$ transmitted signal can be obtained from the horizontal and vertical intensity profiles measured along the red lines drawn in Fig. 2(b). Corresponding absorbance plots (measured at $110 \mathrm{GHz}$ ) are associated with Fig. 2(b), with the classical calculation Absorbance $=\log \left(I_{0} / I\right)$, where $I_{0}$ is the transmitted $\mathrm{THz}$ signal measured out of the sample and $I$ is the transmitted $\mathrm{THz}$ signal measured along the horizontal or vertical profile. Inside the jar, the absorbance varies from 1.2 (empty neck) to 3.9 (full bottom). The measurement of the absorbance in the bottom of the jar is limited by the sensitivity of the detector, which attains the noise level owing to the large thickness of the object in this area (approximately $8 \mathrm{~cm}$ ). Surprisingly, a lower signal intensity region (absorbance around 2.5) can be observed in the bottom part of the jar (see 2D image and vertical slice around abscissa 2.5). This nearly $1 \mathrm{~cm}^{2}$ area may be attributed to the presence of a lower density material, although its origin and composition remain unknown.

The second jar (museum inventory number 8608) is presented in Fig. 3(a). According to curators, shaking the object indicates that it contains an internal material that is not attached to the pottery. However, as explained in Sec. 1, x-ray imaging cannot be performed on this historic and unique object in order to reveal its internal contents due 

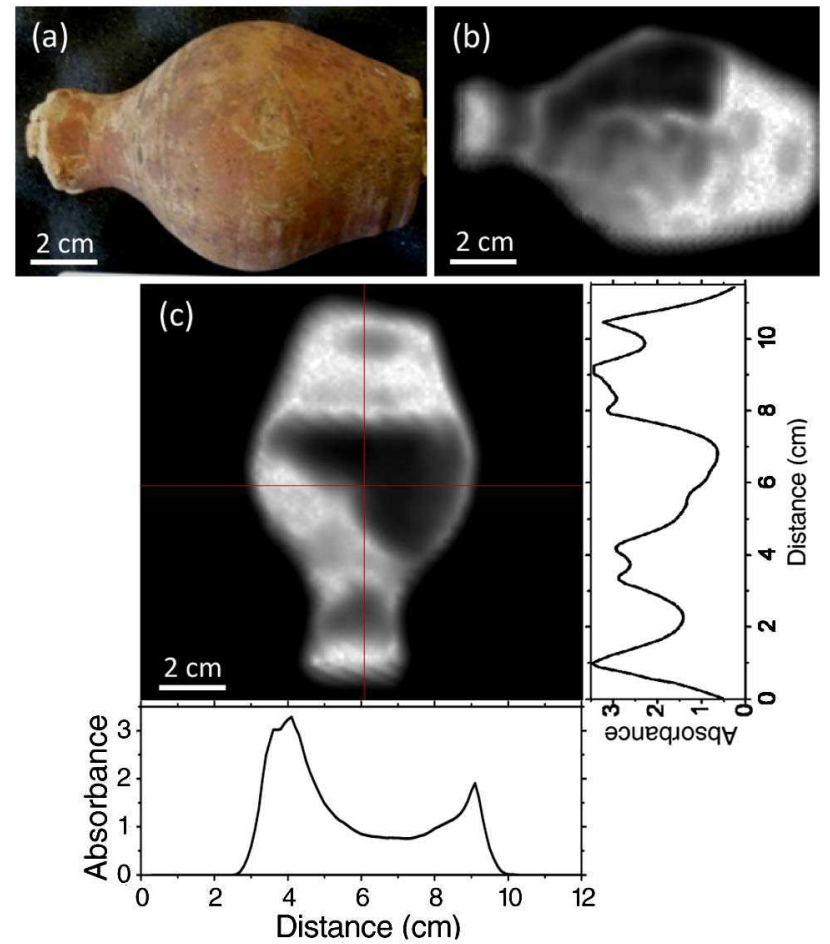

Fig. 3. (Color online) (a) Photograph of the Egyptian jar (inventory number 8608 ). (b) $2 \mathrm{D} \mathrm{THz}$ transmission image from the horizontal jar. (c) $2 \mathrm{D} \mathrm{THz}$ transmission image from the jar turned upside-down and intensity profiles (absorbance) along the horizontal and vertical red lines (Media 1).

to irreversible irradiation and consecutive dating alteration. Figures 3(b) and 3(c) present the THz transmission images of the horizontal jar and the jar turned upside-down, respectively. These positions have been selected in order to determine the presence of the internal contents. As previously explained, due to gravitation effects, mobile contents should move depending on the orientation of the sample. Both images clearly reveal that the jar contains two independent masses, one attached to the bottom and another one free to move inside the internal cavity. Absorbance of both materials can be measured at $110 \mathrm{GHz}$ from the horizontal and vertical profiles along the red lines [Fig. 3(c)]. The fixed bottom material exhibits a global absorbance around 3.4 with a lower absorbance zone (absorbance around 2.3 ) close to the base of the pot. The origin of the lower density area remains unknown. In the central part of the pottery bottle, the mean absorbance is around 0.8 , corresponding to an empty part of the jar. This absorption is simply attributed to the thickness of the pottery walls. At last, the area concerning the mobile contents is characterized by a mean absorbance around 3. Here, we would like to emphasize that $\mathrm{THz}$ analysis of the object reveals an important feature concerning the physical aspect of the unidentified mobile contents. From Figs. 3(b) and 3(c), we can now surely affirm that the contents are deformable since their shape can fit the inner contour of the pottery bottle. From these absorbance measure- ments, and assuming a constant and homogeneous pottery wall thickness, we can also estimate that the absorbance corresponding to the fixed and mobile contents themselves, without the contribution of the pottery walls, should be around 2.6 and 2.2, respectively. The $110 \mathrm{GHz}$ absorption coefficients of the materials characterizing these contents will be estimated in Subsec. 3.B from the 3D THz imaging and thickness measurements.

\section{B. 3D THz Computed Tomography}

To evaluate the volume of the internal materials of the second jar, we finally performed a 3D computed tomographic analysis of the object. The tomography has been completed by rotating the object in an upside-down position around the vertical axis in order to reveal the $3 \mathrm{D}$ geometrical aspects of both solid and mobile contents, previously identified using $2 \mathrm{D} \mathrm{THz}$ imaging.

The media file associated with Fig. 3(c) presents the tilted series obtained from 18 projections (rotation step of $10^{\circ}$ ). From these projection data, we were able to reconstruct and visualize the volume of the jar. Figure 4(a) represents the $3 \mathrm{D} \mathrm{THz}$ video recording of the complete object obtained with a volumerendering software. From the reconstruction, the internal volume of the bottle has been estimated to be $650 \mathrm{~cm}^{3}$. With the volume-rendering software, it is also possible to visualize independently the different parts of the object. Figure $4(\mathrm{~b})$ presents the $3 \mathrm{D} \mathrm{THz}$ video recording of the bottom solid contents of the jar with an estimated volume of $125 \mathrm{~cm}^{3}$. Moreover,
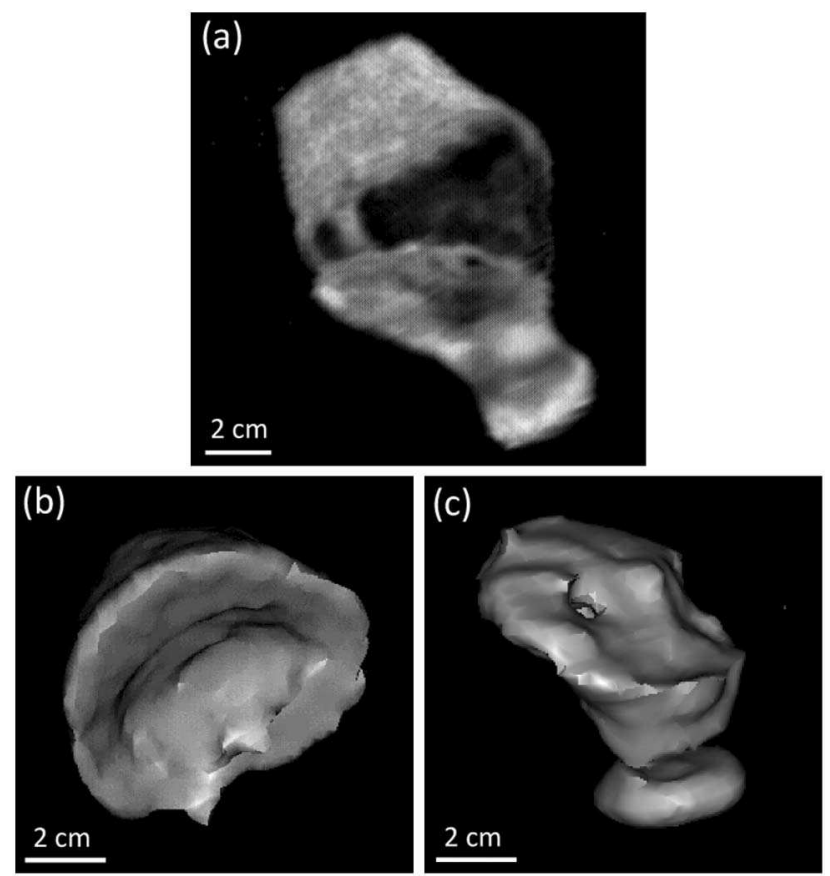

Fig. 4. 3D THz computed tomography of the Egyptian jar (inventory number 8608), turned upside-down. (a) Complete 3D reconstruction of the jar (Media 2). (b) 3D reconstruction of bottom jar contents (Media 3). (c) 3D reconstruction of mobile contents (Media 4). 
the $3 \mathrm{D}$ reconstruction makes it possible to reveal a trough in the central part of the contents, which was not visible from the $2 \mathrm{D} \mathrm{THz}$ images in Fig. 3. Finally, Fig. 4(c) presents the $3 \mathrm{D} \mathrm{THz}$ video recording of the deformable mobile contents with an estimated volume of $25 \mathrm{~cm}^{3}$. As explained previously, from the tilted series and the $3 \mathrm{D}$ reconstructions (see the media files associated with Figs. 3(c) and 4(a)-4(c)), we can measure the dimensions of the fixed and mobile contents of the jar and the global thickness of the pottery wall. Assuming that the thickness of the pottery wall varies from 5 to $8 \mathrm{~mm}$, we first can estimate the $110 \mathrm{GHz}$ absorption coefficients $\alpha$ of the wall jar according to the expression Absorbance $=\alpha l$, where $l$ is the distance the THz-wave travels through the materials. For the pottery wall, taking into account measurement uncertainties, we found $\alpha=1.3 \pm 0.3 \mathrm{~cm}^{-1}$, the large uncertainty coming from the difficult evaluation of the wall thickness owing to the limited transverse spatial resolution. Taking into account this wall absorbance, we can finally deduce the $110 \mathrm{GHz}$ absorption coefficients of the internal contents. For the fixed and the mobile contents, taking into account measurement uncertainties, we found the same absorption coefficient: $\alpha=0.7 \pm 0.15 \mathrm{~cm}^{-1}$. This result indicates that the fixed and mobile contents could be constituted of the same material, even if its nature remains unknown. As previously explained, according to Egyptologists, these contents could consist of residual dried materials, probably organic, resulting from possible funerary offerings. At present, to further investigate the pottery's origin, the irreversible opening of the jars would be necessary in order to perform complementary chemical analysis of the internal contents. After our analysis, we can point out that $\mathrm{THz}$ imaging let us know that the jars have to be opened in order to penetrate their secrets deeper.

\section{Conclusion}

$2 \mathrm{D}$ and $3 \mathrm{D} \mathrm{THz}$ imaging revealed internal contents in two XVIIIth Dynasty Egyptian sealed pieces of pottery, preserved at the Museum of Aquitaine. Although this presence could be also imaged using $\mathrm{x}$-ray imaging, we pointed out that this additional measurement would alter the integrity of these unique objects owing to the irreversible irradiation action. We demonstrated here the potential of $\mathrm{THz}$ imaging for the detection of hidden materials in historic objects. Especially for the investigation of Egyptian antiquities, the technique may be used in the future for the noninvasive and nondestructive analysis of canopic jars used as specific containers by the Egyptians to store and preserve the viscera during the rituals of mummification.

The authors gratefully acknowledge François Hubert, director of the Museum of Aquitaine, and the city of Bordeaux for the authorization to perform the measurements at the museum. They also acknowledge Magalie Rouillon and Theo Goltzman for additional fruitful discussions concerning the description of the Egyptian jars.

\section{References}

1. J. B. Jackson, M. Mourou, J. F. Whitaker, I. N. Duling III, S. L. Williamson, M. Menu, and G. A. Mourou, "Terahertz imaging for non-destructive evaluation of mural paintings," Opt. Commun. 281, 527-532 (2008).

2. K. Fukunaga, K. Osako, Y. Kohdzuma, T. Koezuka, M.-J. Kim, T. Ikari, and X. Du, "Terahertz analysis of an East Asian historical mural painting," J. Eur. Opt. Soc. Rapid Pub. 5, 10024 (2010).

3. A. J. L. Adam, P. C. M. Planken, S. Meloni, and J. Dik, "TeraHertz imaging of hidden paint layers on canvas," Opt. Express 17, 3407-3416 (2009).

4. E. Abraham, A. Younus, J.-C. Delagnes, and P. Mounaix, "Noninvasive investigation of art paintings by terahertz imaging," Appl. Phys. A 100, 585-590 (2010).

5. J. Labaune, J. B. Jackson, S. Pagès-Camagna, I. N. Duling, M. Menu, and G. A. Mourou, "Papyrus imaging with terahertz time domain spectroscopy," Appl. Phys. A 100, 607-612 (2010).

6. L. Öhrström, A. Bitzer, M. Walther, and F. J. Rühli, "Technical note: Terahertz imaging of ancient mummies and bone," Am. J. Phys. Anthropol. 142, 497-500 (2010).

7. M. J. Aitken, Thermoluminescence Dating (Academic, 1985).

8. B. Recur, A. Younus, S. Salort, P. Mounaix, B. Chassagne, P. Desbarats, J.-P. Caumes, and E. Abraham, "Investigation on reconstruction methods applied to 3D terahertz computed tomography," Opt. Express 19, 5105-5117 (2011).

9. B. Ferguson, S. Wang, D. Gray, D. Abbot, and X. C. Zhang, "Tray computed tomography," Opt. Lett. 27, 1312-1314 (2002).

10. E. Abraham, A. Younus, C. Aguerre, P. Desbarats, and P. Mounaix, "Refraction losses in terahertz computed tomography," Opt. Commun. 283, 2050-2055 (2010).

11. S. Wang and X. C. Zhang, "Pulsed terahertz tomography," J. Phys. D 37, R1-R36 (2004).

12. A. Brahm, M. Kunz, S. Riehemann, G. Notni, and A. Tünnermann, "Volumetric spectral analysis of materials using terahertz-tomography techniques," Appl. Phys. B 100, 151-158 (2010).

13. E. Kato, S. Nishina, A. Irisawa, T. Yamashita, M. Imamura, and K. Kawase, "3D spectroscopic computed tomography imaging using terahertz waves," in Proceedings of IEEE Conference on 35th International Conference on Infrared, Millimeter and Terahertz Waves (IEEE, 2010), Mo-P.67.

14. C. Pradere, J.-P. Caumes, D. Balageas, S. Salort, E. Abraham, B. Chassagne, and J.-C. Batsale, "Photothermal converters for quantitative 2D and 3D real-time terahertz imaging," Quant. InfraRed Thermogr. 7, 217-235 (2010).

15. G. T. Herman, Image Reconstruction from Projections : The Fundamentals of Computerized Tomography (Academic, 1980).

16. J. Radon, "Uber die Bestimmung von Funktionen durch ihre Integralwerte langs gewisser Mannigfaltigkeiten," Ber. Verh. Sachs. Akad. Wiss. Leipzig Math-Phys. Kl. 69, 262-277 (1917). In German. An English translation can be found in S. R. Deans, The Radon Transform and Some of its Applications (Wiley, 1983).

17. A. H. Andersen and A. C. Kak, "Simultaneous algebraic reconstruction technique (SART) : A superior implementation of the ART algorithm," Ultrasonic Imaging 6, 81-94 (1984).

18. F. Saragoza, "La collection thébaine du Dr Godard au musée d'Aquitaine," Revue archéologique de Bordeaux, tome IC 131-151 (2008). In French. 